\title{
Interleukin-8 Production by Human Gingival Fibroblasts in Response to Periodontopathic Bacterial Lipopolysaccharides and Prostaglandin $\mathrm{E}_{2}$ In vitro.
}

\author{
Takeo Fujii ${ }^{1,3)}$, Pao-Li Wang ${ }^{2)}$, Toshihiko Yajima ${ }^{1)}$, Anne Carrel-Geinoz ${ }^{3)}$, Shyuhei Usui ${ }^{2}$, Junichi Otogoto ${ }^{2)}$, \\ Norio $\mathrm{Ota}^{2)}$ and Pierre C. Baehni ${ }^{3)}$
}

\author{
1)Institute of Medical Science, and Department of Oral Anatomy, Health Sciences University of Hokkaido, Japan \\ ${ }^{2}$ Departments of Pharmacology and Periodontology, Matsumoto Dental University, Japan \\ ${ }^{3}$ Department of Preventive Dentistry, School of Dental Medicine, University of Geneva, Switzerland \\ (Acecceped for publication, Feburary 14,2004)
}

\begin{abstract}
This study examined the modulating effect of $\mathrm{PGE}_{2}$ on LPS-induced IL-8 production by human gingival fibroblasts in vitro. The expression of IL-8 mRNA, after stimulation with $\mathrm{PGE}_{2}$, was determined by RT-PCR. IL-8 production by HGFs was shown to be related to the time of incubation and the dose of LPS. A slight increase in IL-8 levels was observed when cells were exposed to PGE 2 alone compared to controls. When HGFs were pre-stimulated with PGE, and then exposed to LPS, IL-8 production was increased 2-3 fold compared to non-treated cells. Herbimycin A completely abolished the secretion of IL-8. These results indicate that $\mathrm{PGE}_{2}$ can modulate cytokine secretion from HGFs and increase IL-8 production from cells exposed to LPS. IL-8 production induced by LPS was dependent on the tyrosine phosphorylation pathway.
\end{abstract}

Key words: human gingival fibroblasts, interleukin-8, lipopolysaccharides, prostaglandin $E_{2}$.

\section{Introduction}

Human gingival fibroblasts (HGFs), which represent the major cellular component of the gingival connective tissues, have an important function in maintaining the integrity of the gingiva. HGFs may also play a significant role in the pathogenesis of periodontal disease. Indeed, over the past few years several studies have reported cytokine production by HGFs in response to bacterial components and inflammatory mediators. Thus, it is conceivable that these cytokines may participate in tissue remodeling which occurs during the active phase of periodontal destruction ${ }^{1)}$

The colonization of the tooth surface by micro-organisms triggers an inflammatory reaction within the gingival tissues accompanied by a destruction of the collagen fibers. In the early phase of disease, the inflammatory infiltrate is composed mainly of polymorphonuclear leukocytes. The migration of inflammatory

Correspondence to Takeo Fujii, Institute of Medical Science, Health Sciences University of Hokkaido, 2-5 Ainosato, Kita-ku, Sapporo $002-$ 8072, Japan.Tel: +81-11-778-7558; Fax: +81-11-770-5034 E-mail: tfujii@hoku-iryo-u.ac.jp cells within the connective tissues could be due to chemotactic factors of bacterial origin. However, it is also possible that the reaction is host mediated and that inflammatory cells are attracted by mediators produced locally by resident cells. Several studies have demonstrated that human dermal fibroblasts have the ability to produce proinflammatory interleukins ${ }^{2,3)}$ including interleukin8 (IL-8), a known neutrophil activating/chemotactic factor ${ }^{4}$. Synthesis and secretion of IL-8 has also been demonstrated for human gingival fibroblasts ${ }^{5-9)}$ IL- 8 production by HGFs may be induced by bacterial components as well as mediators such as IL-1 and TNF-aa from immunocompetent cells ${ }^{6-8}$.

It is generally agreed that oral bacteria such as Porphyromonas gingivalis and Actinobacillus actinomycetemcomitans are important in the etiology of periodontal diseases. Lipopolysaccharides (LPS) from these pathogens have been implicated in pathogenesis of disease because of their ability to induce an inflammatory and immune response as well as periodontal tissue breakdown ${ }^{10-12)}$. However, little is known about the effect of LPS from periodontopathic bacteria on the production of proinflammatory cytokines by resident cells such as HGFs. 
Takeo FUJII et al: Effect of PGE2 on IL-8 production

Furthermore, the exact role of prostaglandin $\mathrm{E}_{2}\left(\mathrm{PGE}_{2}\right)$ in potentiating cytokine production is not well understood. $\mathrm{PGE}_{2}$ is a potent mediator of inflammation which has been detected in inflamed gingival tissues and in gingival crevicular fluid ${ }^{13-16)}$. Samples from inflamed sites showed elevated levels of $\mathrm{PGE}_{2}$ as compared to non-inflamed sites ${ }^{17-19)}$. One could speculate that increased levels of $\mathrm{PGE}_{2}$ may be of importance in the disease process by regulating fibroblast functions.

The purpose of the present investigation was to explore the ability of periodontopathic bacterial LPS to modulate IL-8 production and to examine the effects of $\mathrm{PGE}_{2}$ priming on LPSinduced production of IL- 8 by HGFs in vitro.

\section{Materials and Methods \\ Preparation of human gingival fibroblasts}

Human gingival fibroblasts were obtained from nine healthy donors. Cells were derived from biopsies of the attached gingiva that were clinically free of periodontal disease. The gingival tissues were minced in Dulbecco's modified Eagle's medium (DMEM; Gibco, Grand Island, NY, USA). Tissue fragments were placed in $35 \mathrm{~mm}$ plastic dishes (Falcon, Pharmacia Fine Chemicals, Uppsala, Sweden) and cultured in medium containing $100 \mu \mathrm{g} / \mathrm{ml}$ of streptomycin, $100 \mathrm{units} / \mathrm{ml}$ of penicillin $\mathrm{G}$ and $10 \%$ heatinactivated fetal calf serum (FCS; Gibco) in a humidified atmosphere of $5 \% \mathrm{CO}_{2}$ at $37^{\circ} \mathrm{C}$. Cells were used between the 2 nd and the 8 th passage. HGFs were seeded at a cell density of $1 \times 10^{4}$ cells/well in 96-well microtiter plates 3 days prior to the experiments. The culture medium was then removed and replaced with DMEM supplemented with $1 \%$ FCS for $24 \mathrm{~h}$. Cultures were washed with DMEM and exposed to LPS preparations or $\mathrm{PGE}_{2}$. All experiments were performed in duplicate.

\section{Lipopolysaccharides}

Lipopolysaccharides from Porphyromonas gingivalis 381 ( $P g$ LPS) and Actinobacillus actinomycetem-comitans ATCC 29523 ( $A a$-LPS) were kindly provided by Dr. T. Nishihara, Department of Oral Science, The National Institute of Health, Tokyo, Japan. LPS was extracted from lyophilized cells of $P$. gingivalis and $A$. actinomycetemcomitans by the hot phenol-water procedure ${ }^{201}$. LPS from Escherichia coli 0127:B8 (Ec-LPS) was purchased from Difco Laboratories (Detroit, Mich, USA) and used as standard.

\section{Stimulation with LPS}

Cultures were stimulated by exposing HGFs to LPS under different experimental conditions.

(a) HGFs were exposed for $4 \mathrm{~h}$ to $E c$-, $P g$-, or $A a$-LPS (0.001-10 $\mu \mathrm{g} / \mathrm{ml})$ in the presence of $1 \%$ serum. After replacing the culture medium by medium containing no LPS, cultures were further incubated for $4 \mathrm{~h}$.

(b) HGFs were exposed for $4 \mathrm{~h}$ to $E c$-LPS or $A a$-LPS $(0.001-10$ $\mu \mathrm{g} / \mathrm{ml})$ in the presence of $0-5 \% \mathrm{FCS}$. (c) HGFs were exposed to herbimycin A $(10 \mu \mathrm{g} / \mathrm{ml})$ for $1 \mathrm{~h}$ before LPS stimulation.

(d) HGFs were exposed to LPS preparations $(10 \mu \mathrm{g} / \mathrm{ml})$ for various periods of time up to $24 \mathrm{~h}$ in the presence of $1 \%$ serum.

(e) HGFs were pre-stimulated with $10^{-5} \mathrm{M}$ of $\mathrm{PGE}_{2}$ for $2 \mathrm{~h}$, washed twice with DMEM and then exposed to LPS for up to $24 \mathrm{~h}$.

Activation of cells by $\mathrm{PGE}_{2}$

To evaluate the effect of $\mathrm{PGE}_{2}$ on LPS-induced IL-8 production, cultures were pre-stimulated with various concentrations $\left(10^{-7} \mathrm{M}\right.$ to $10^{-5} \mathrm{M}$ ) of $\mathrm{PGE}_{2}$ (Sigma) for up to $2 \mathrm{~h}$ before adding the LPS preparations. Cultures were then exposed to $10 \mu \mathrm{g} / \mathrm{ml}$ of Ec-, $P g-$ or $A a$-LPS for various times up to $24 \mathrm{~h}$.

\section{Assay of $I L-8$}

Following incubation, culture supernatants were collected and centrifuged at $3000 \mathrm{~g}$ for 2 minutes and stored at $4^{\circ} \mathrm{C}$ until assayed for IL- 8 content. The activity of IL- 8 was measured using a commercial kit (Pelikine Compact ${ }^{\mathrm{TM}}$ human IL-8 ELISA Kit, Central Laboratory of The Netherlands Red Cross Blood Transfusion Service, Amsterdam, The Netherlands). IL-8 concentration was determined by comparing the optical density of the samples to a standard curve. The cell culture supernatants incubated with medium alone without activating agents were used as controls.

\section{IL-8 mRNA expression}

Total RNA was extracted from control HGFs and cells exposed to $\mathrm{PGE}_{2}$ using Trizol R and quantified by spectrophotometry. Reverse transcription reaction was carried out in a $20-\mu 1$ volume containing $1.0 \mu \mathrm{g}$ total RNA, $2.5 \mathrm{U}$ RNasin, $5 \mathrm{mM} \mathrm{MgCl}, 50$ $\mathrm{mM} \mathrm{KCl}, 10 \mathrm{mM}$ Tris (pH 8.3), $2.0 \mu \mathrm{M}$ oligo (dT) $11-18$ primer, and $10 \mathrm{U}$ of reverse transcriptase. The samples were incubated at $37^{\circ} \mathrm{C}$ for $1 \mathrm{~h}$. Reverse transcriptase was inactivated by incubation at $95^{\circ} \mathrm{C}$ for 7 minutes. For each amplification reaction (PCR), 2 $\mu 1$ cDNA (equivalent to $100 \mathrm{ng}$ total RNA) was used. Each $100 \mu \mathrm{l}$ reaction consisted of $10 \mathrm{mM}$ Tris- $\mathrm{HCl}, 50 \mathrm{mM} \mathrm{KCl}, 0.2 \%$ Triton $\mathrm{X}-100,1.5 \mathrm{mM} \mathrm{MgCl}$, and $0.2 \mathrm{mM}$ each of dATP, dCTP, dGTP, and dTTP. Sense and anti-sense IL-8 primer was purchased from CLONTECH Laboratories (Palo Alto, Ca, USA).

IL-8 sequence information:

Upstream( $\left.5^{\prime}\right)$

primer; 5'-ATGACTTCCAAGCTGGCCGTGGCT-3'

Downstream (3')

primer; 5'-TC TCAGCCCTCTTCAAAAACTTCTC-3'

Amplification was carried out for 30 cycles. The amplification reaction profile consisted of denaturation at $94^{\circ} \mathrm{C}$ for $45 \mathrm{sec}$, primer annealing at $60^{\circ} \mathrm{C}$ for 45 seconds, and primer extension at $72^{\circ} \mathrm{C}$ for 2 minutes. Additionally, sense and anti-sense primers for GAPDH were included in the reaction as internal controls. The 
amplification for GAPDH was performed for 30 cycles. The amplification products were electrophoresed in $2 \%$ agarose gels containing $0.5 \mu \mathrm{g} / \mathrm{ml}$ ethidium bromide.

Statistical analysis

The paired $t$-test was used to assess the significance of the observed differences. The differences were considered significant when the probability $(p)$ value was $<0.05$.

\section{Results}

\section{IL-8 production by HGFs exposed to LPS}

HGFs cultures exposed to $E c$-, $P g$-, and $A a$-LPS showed a significant increase in IL-8 levels when compared to controls (Fig. 1A). In Ec- and Pg-LPS stimulated cultures IL-8 levels were dependent on the dose of LPS used with a maximum release at 10 $\mu \mathrm{g} / \mathrm{ml}$. At this concentration, Pg-LPS was more potent in stimulating IL-8 release compared to Ec-LPS with a 7.2 and 3.4 fold increase over control cells respectively $(p<0.01)$. Aa-LPS also induced IL-8 secretion in a dose-dependent fashion at low concentrations but reached a plateau at $0.1 \mu \mathrm{g} / \mathrm{ml}$.

When the incubation medium was removed and replaced by fresh medium containing no LPS, HGFs continued to release IL8 (Fig. 1B). After 4 h, IL-8 levels were found to be significantly higher in LPS pre-stimulated culture supernatants than in control cultures $(p<0.01)$. IL-8 release was dependent on the dose of LPS used during the stimulation period and was the highest with $\mathrm{Pg}$ LPS at a concentration of $10 \mu \mathrm{g} / \mathrm{ml}$. Cultures pre-exposed to $A a-$ LPS also showed a significant increase in IL- 8 levels at low doses which leveled off at $0.1 \mu \mathrm{g} / \mathrm{ml}$. There was no difference in the morphology of control cultures and cells exposed to LPS. Cell vitality, as assessed by violet blue staining, was $>90 \%$ (data not shown).

\section{Effect of serum on IL-8 production}

The effect of serum was examined by exposing HGFs cultures to $E c$ - or $A a$-LPS in the presence of various serum concentrations ranging from $0-5 \% \mathrm{FCS}$. In serum-free conditions, $E c$-LPS and $A a$-LPS induced low levels of IL-8, ranging from 118-1788 pg/ $\mathrm{ml}$ and $332-1194 \mathrm{pg} / \mathrm{ml}$ respectively. With both LPS preparations, addition of $1 \%$ or $5 \%$ FCS to the culture medium greatly enhanced IL-8 secretion with levels 2-10 fold higher than in serum-free conditions (data not shown).

\section{Effect of herbimycin A on IL-8 secretion}

When herbimycin A treated cells were exposed to the various LPS preparations (concentrations 0.001-10 $\mu \mathrm{g} / \mathrm{ml} \mathrm{Ec-,} \mathrm{Pg-,} \mathrm{Aa}$ LPS) IL-8 secretion by HGFs was completely inhibited. This was observed both during the exposure of cells to LPS as well as after removing LPS preparations from the medium $(p<0.01)$ (data not shown).

IL-8 production by HGFs exposed to LPS for various periods of time

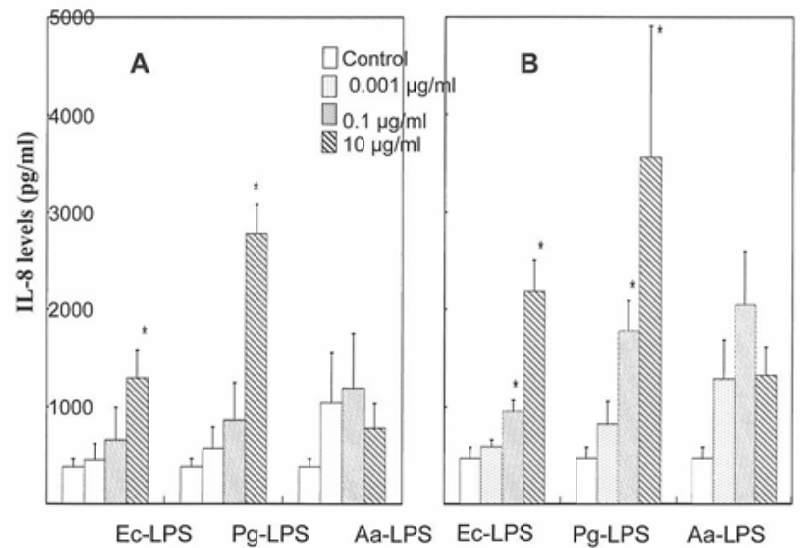

Fig. 1. IL-8 production by HGFs exposed to LPS (A) and after removing LPS (B). (A) HGFs were exposed for $4 \mathrm{~h}$ to various concentrations (0.001$10 \mathrm{mmg} / \mathrm{ml}$ ) of $E c$-LPS, $P g$-LPS or $A a$-LPS. (B) Following LPS stimulation, medium was replaced by medium without LPS and cultures were further incubated for $4 \mathrm{~h}$. Data is reported as the mean plus standard deviation of 4 different experiments. ${ }^{*}$ : Significant increase compared to control cultures $(p<0.01)$.

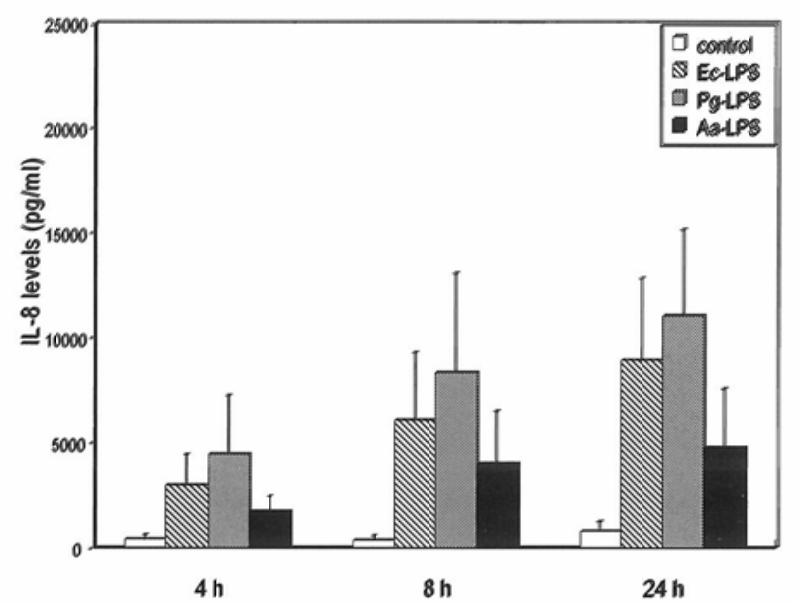

Fig. 2. IL-8 production by HGFs exposed to LPS for various periods of time. Cells were exposed to $10 \mathrm{mmg} / \mathrm{ml}$ of $E c$-LPS or Pg-LPS or $A a$-LPS for up to $24 \mathrm{~h}$. Data is reported as the mean plus standard deviation of 5 different experiments.

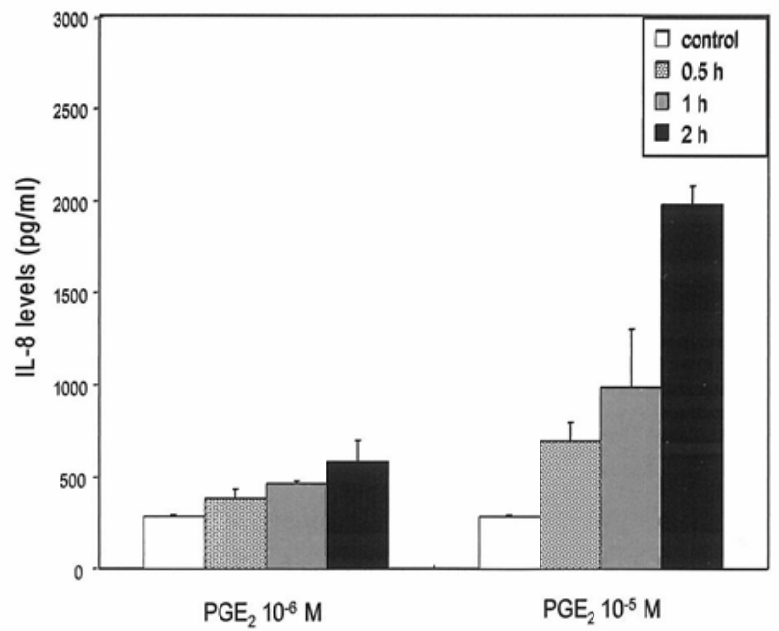

Fig. 3. Effect of $\mathrm{PGE}_{2}$ on IL-8 production by HGFs. Cells were stimulated with various concentrations of $\mathrm{PGE}_{2}\left(10^{-7} \mathrm{M}\right.$ to $\left.10^{-5} \mathrm{M}\right)$ for up to $2 \mathrm{~h}$. Each point represents the mean plus standard error of duplicate values. 
Takeo FUJII et al: Effect of PGE2 on IL-8 production

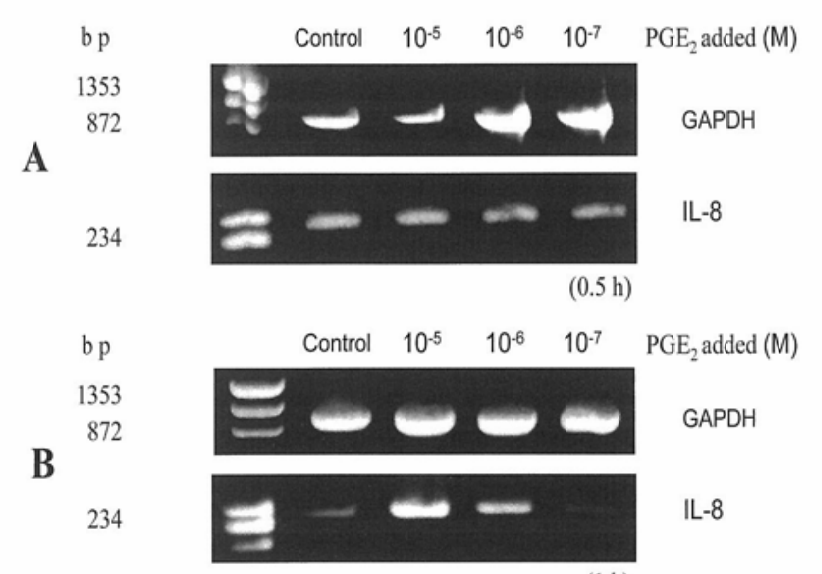

(1 h)

Fig. 4. Effect of $\mathrm{PGE}_{2}$ on IL-8 mRNA as assessed by RT-PCR. Each amplification was carried out for 30 cycles. (A) $0.5 \mathrm{~h}$, (B) $1 \mathrm{~h}$ exposure to $\mathrm{PGE}_{2}\left(10^{-7} \mathrm{M}\right.$ to $\left.10^{-5} \mathrm{M}\right)$.

As shown in Fig. 2, secretion of IL-8 increased in a timedependent fashion with all LPS tested. $P g$-LPS was the most potent in stimulating IL-8 production and was approximately 2 times higher than $A a$-LPS at each observation time.

\section{Effect of $P G E_{2}$ on $I L-8$ production}

Cell cultures exposed to $10^{-5} \mathrm{M} \mathrm{PGE}_{2}$ alone showed a modest but significant increase in IL-8 production compared to control cultures. The increase in IL- 8 was dependent on the time of exposure as can be seen in Fig. 3. Cells were much less responsive to $10^{-6} \mathrm{MPGE}_{2}$, whereas $10^{-7} \mathrm{M} \mathrm{PGE}_{2}$ had only a limited effect (data not shown). No difference in the expression of IL-8 mRNA between control and $\mathrm{PGE}_{2}$ stimulated cells was detected after 0.5 h exposure (Fig. 4A). However, mRNA expression was clearly enhanced when cultures were stimulated with $\operatorname{PGE}_{2}\left(10^{-5} \mathrm{M}\right)$ for 1 h (Fig. 4B).

We also examined the response of $\mathrm{PGE}_{2}$-activated cells to $E c$-, $P g$ - or $A a$-LPS by exposing the cultures to $\mathrm{PGE}_{2}\left(10^{-5} \mathrm{M}\right)$ for $2 \mathrm{~h}$ before adding the LPS preparations. As can be seen in Fig. 5, IL8 production was time-dependent and increased up to $24 \mathrm{~h}$ with all LPS tested. Highest levels of IL-8 were found in cultures stimulated with $P g$-LPS. When comparing the results obtained with $\mathrm{PGE}_{2}$-treated cells (Fig. 5) and those with untreated cells (Fig. 2), production of IL-8 was significantly increased in activated cultures.

Table 1 summarizes IL- 8 data of $\mathrm{PGE}_{2}$-activated cells obtained from five experiments using four different cell lines. A 2-3 foldincrease in IL-8 levels was observed with $\mathrm{PGE}_{2}$-activated cells compared to non-activated cells. Statistical significance was seen at $4 \mathrm{~h}$ stimulation with all LPS tested $(p<0.05)$ and at $8 \mathrm{~h}$ stimulation with $E c$ - and $P g$-LPS $(p<0.05)$.

\section{Discussion}

LPS from periodontal pathogens have been shown to stimulate

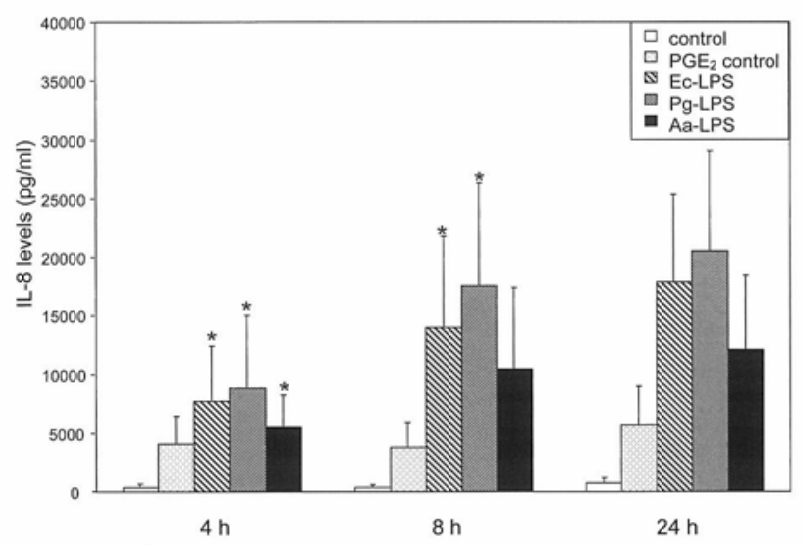

Fig. 5. Effect of $\mathrm{PGE}_{2}$ activation on LPS-induced IL-8 production. After incubation with $\mathrm{PGE}_{2}$ for $2 \mathrm{~h}$, cells were exposed to $10 \mathrm{mmg} / \mathrm{ml}$ of $E c$-LPS or $P g$-LPS or $A a$-LPS for up to $24 \mathrm{~h}$. Data is reported as the mean plus standard deviation from five different experiments. *: Significant increase compared with non-activated cells $(p<<0.05)$.

Table1. Mean fold-increase of IL-8 production in PGE2-pretreated HGFs

\begin{tabular}{cccc}
\hline \hline & & & \\
& $4 \mathrm{~h}$ & $8 \mathrm{~h}$ & $24 \mathrm{~h}$ \\
\hline PGE2+Ec- LPS & $2.4 \pm 0.6^{\mathrm{a} *}$ & $2.3 \pm 0.6^{*}$ & $2.4 \pm 1.1$ \\
PGE2+Pg- LPS & $1.8 \pm 0.2^{*}$ & $2.3 \pm 0.4^{*}$ & $1.9 \pm 0.6$ \\
PGE2+Aa- LPS & $3.1 \pm 0.7^{*}$ & $2.4 \pm 0.3$ & $3.0 \pm 1.1$ \\
\hline
\end{tabular}

a Mean standard deviation (data from 5 different experiments)

* Significantly different from cultures stimulated with LPS alone $(\mathrm{p}<0.05)$

IL-8 mRNA expression and IL-8 synthesis in human gingival ${ }^{6)}$ as well as periodontal ligament fibroblast cultures ${ }^{21)}$ More recently, A. actinomycetemcomitans and Campylobacter rectus were reported to induce secretion of IL-8 as well as IL-6 by HGFs ${ }^{10-12)}$. Under the present experimental conditions, $P g$-LPS was more potent in inducing IL-8 production than the other LPS tested. These observations may be related to differences in the structure of LPS molecules between the bacteria tested or to variations in LPS receptors on mammalian cells ${ }^{22)}$. Several reports have indicated that the chemical composition and biological properties of LPS may vary among periodontopathic bacteria ${ }^{23,24)} \mathrm{A}$ recent study reported that $P$. gingivalis LPS contained larger amounts of carbohydrates than A. actinomycetemcomitans, Fusobacterium nucleatum and Capnocytophaga ochracea LPS whereas fatty acid content was lower in $P$. gingivalis compared to the other pathogens ${ }^{25}$ Other characteristic features ${ }^{26)}$ have been described for the LPS structure of $P$. gingivalis ${ }^{27,}{ }^{28}$ and $A$. actinomycetemcomitans ${ }^{29,30)}$. Thus, it is possible that differences in LPS structure may affect the recognition and interaction of the LPS molecule with the membrane receptors of the HGFs. Exposure of HGF cultures to herbimycin A before LPS stimulation resulted in a complete inhibition of IL-8 synthesis. Herbimycin A is known to be a potent inhibitor of the tyrosine kinase system as 
it binds in an irreversible fashion to the thiol groups of tyrosine kinase $^{31)}$. It has been shown to be an effective inhibitor of LPSinduced protein tyrosine phosphorylation in human macrophages. Thus, the results suggest that the up-regulation of IL- 8 production by HGFs in response to LPS is dependent on the tyrosine kinase system.

A previous report indicated that $\mathrm{PGE}_{2}$ enhances IL-8 production by human synovial fibroblasts in cultures upon stimulation with IL-1 ${ }^{32)}$. We also showed that pre-activation of HGFs with $\mathrm{PGE}_{2}$ before exposure to LPS resulted in a 2-3 fold increase in the levels of IL 8 production compared to non-activated cells. IL- 8 production patterns with $\mathrm{PGE}_{2}$-treated cells were similar to those observed under standard experimental conditions: $E c$-LPS and $P g$-LPS were more potent than $A a$-LPS in stimulating IL- 8 release. These observations suggest that $\mathrm{PGE}_{2}$ did not affect the binding affinity of SCD14-LPS complexes to HGFs but activated cell function ${ }^{1)}$. PGE receptor has been shown to be coupled to cell membrane $\mathrm{G}$-proteins ${ }^{33}$. $\mathrm{PGE}_{2}$, through its binding to these specific receptors, can enhance cAMP levels through stimulation of adenylate cyclase metabolism ${ }^{34}$. Lenardo et $a l . .^{35)}$ suggested that increasing cAMP levels is essential for the expression and regulation of IL- $1 \mathrm{bb}$, IL-6, and TNF-aa genes. It is not known if production of IL- 8 by PGE $_{2}$-treated HGFs is regulated by similar mechanisms. Our findings with $\mathrm{PGE}_{2}$ are in contrast with previous observations with other human cell types ${ }^{36,37)}$. Others reported that $\mathrm{PGE}_{2}$ had no effect on LPS-induced IL-8 production in human macrophages and that $\mathrm{PGE}_{2}$ reduced macrophage IL-6 production ${ }^{38}$. It is likely that macrophages and polymorphonuclear cells, whose origin differs basically from HGFs, are terminally differentiated phagocytes that may have lost the ability for $\mathrm{PGE}_{2}$ to regulate their IL-8 expression.

There is strong evidence that LPS from $P$. gingivalis and $A$. actinomycetemcomitans have the potential to stimulate HGFs to release IL- 8 as well as other cytokines. These observations indicate that HGFs can act as accessory immunocompetent cells in gingival tissues. The present results suggest that $\mathrm{PGE}_{2}$ can modulate this role.

\section{Acknowledgements}

We are grateful to Dr. M. Bickel for providing constructive advice. We thank Ms. C. Milano for her help in the preparation of the manuscript. This study was supported by a Grant-inaid for Scientific research(C)(2)(no.13672194)from the Ministry of Education, Science and Culture, Japan.

\section{References}

1. Wang P. and Ohura K.: Porphyromonas gingivalis lipopolysaccharide signaling in gingival fibroblasts $\mathrm{CD} 14$ and tolllike receptors. Crit Rev Oral Biol Med, 13: 132-142, 2002

2. Larsen C.G., Anderson A.O., Oppenheim J.J. and Matsushima K.: Production of interleukin- 8 by human dermal fibroblasts and keratinocytes in response to interleukin- 1 or tumor necrosis factor. Immunology, 68: 31-36, 1989

3. Boxman I.L., Ruwhof C., Boerman O.C., Lowik C.W. and Ponec M.: Role of fibroblasts in the regulation of proinflammatory interleukin IL-1, IL- 6 and IL-8 levels induced by keratinocytederived IL-1. Arch Dermatol Res, 288: 391-398, 1996

4. Baggiolini M., Walz A. and Kunkel S.L.: Neutrophilactivating peptide-1/interleukin 8 , a novel cytokine that activates neutrophils. J Clin Invest, 84: 1045-1049, 1989

5. Matsuki Y., Yamamoto T. and, Hara K.: Detection of inflammatory cytokine messenger RNA (mRNA)-expressing cells in human inflamed gingival by combined in situ hybridization and immunohistochemistry. Immunology, 76 : $42-47,1992$

6. Tamura M., Tokuda M., Nagaoka S. and Takada H.: Lipopolysaccharides of Bacteroides intermedius (Prevotella intermedia) and Bacteroides (Porphyromonas) gingivalis induce interleukin- 8 gene expression in human gingival fibroblast cultures. Infect Immun, 60: 4932-4937, 1992

7. Takashiba S., Takigawa M., Takahashi K., Myokai F., Nishimura F., Chihara T., Kurihara H., Nomura Y. and Murayama Y.: Interleukin-8 is a major neutrophil chemotactic factor derived from cultured human gingival fibroblasts stimulated with interleukin- $1 \mathrm{bb}$ or tumor necrosis factor alpha. Infect Immun, 60: 5253-5258, 1992

8. Takigawa M., Takashiba S., Myokai F., Takahashi K., Arai H., Kurihara H. and Murayama Y.: Cytokine-dependent synergistic regulation of interleukin-8 production from human gingival fibroblasts. J Periodontol, 65: 1002-1007, 1994

9. Dongari-Bagtzoglou A.I. and Ebersole J.L.: Increased presence of interleukin-6 (IL-6) and IL-8 secreting fibroblast subpopulations in adult periodontitis. J Periodontol, 69: 899910,1998

10. Fujiwara T., Ogawa T., Sobue S. and Hamada S.: Chemical, immunobiological and antigenic characterizations of lipopolysaccharides from Bacteroides gingivalis strains. J Gen Microbiol, 136: 319-326, 1990

11. Takada H., Mihara J., Morisaki I. and Hamada S.: Production of cytokines by human gingival fibroblasts. In: Hamada S, Holt S.C. and McGhee J.R., eds. Periodontal Disease; pathogens and host immune responses. Quintessence Publishing Co., Tokyo; 265-276, 1991

12. Wilson M., Reddi K. and Henderson B.: Cytokine-inducing components of periodontopathogenic bacteria. J Periodont Res., 31: 393-407, 1996

13. Goodson J.M., Dewhirst F.E. and Brunetti A.: Prostaglandin $\mathrm{E}_{2}$ levels and human periodontal disease. Prostaglandins, 6 : $81-85,1974$

14. El Attar T.M.A.: Prostaglandin $E_{2}$ in human gingival in health and disease and its stimulation by female sex steroids. Prostaglandins, 11: 331-341, 1976 
Takeo FUJII et al: Effect of PGE2 on IL-8 production

15. El Attar T.M.A. and Lin H.S.: Prostaglandins in gingiva of patients with periodontal disease. J Periodontol, 52: 16-19, 1981

16. Offenbacher S., Farr D.H. and Goodson J.M.: Measurement of prostaglandin $\mathrm{E}$ in crevicular fluid. J Clin Periodontol, 8: 359-367, 1981

17. Dewhirst F.E., Moss D.E., Offenbacher S. and Goodson J.M.: Levels of prostaglandin $\mathrm{E}_{2}$, thromboxane, and prostacyclin in periodontal tissues. J Periodont Res, 18: 156-163, 1983

18. Ohm K., Albers H-K. and Lisboa BP. Measurement of eight prostaglandins in human gingival and periodontal disease using high pressure liquid chromatography and radioimmunoassay. J Periodont Res, 19: 501-511, 1984

19. Offenbacher S., Odle B.M. and Van Dyke T.E.: The use of crevicular fluid prostaglandin $\mathrm{E}_{2}$ levels as a predictor of periodontal attachment loss. J Periodont Res, 21: 101-112, 1986

20. Nishihara T., Ohsaki Y., Ueda N., Saito N. and Mundy G.R.: Mouse interleukin-1 receptor antagonist induced by Actinobacillus actinomycetemcomitans lipopolysaccharide blocks the effects of interleukin-1 on bone resorption and osteoclast-like cell formation. Infect Immun 62: 390-397, 1994

21. Yamaji Y., Kubota T., Sasaguri K., Sato S., Suzuki Y., Kumada $\mathrm{H}$. and Umemoto T.: Inflammatory cytokine gene expression in human periodontal ligament fibroblasts stimulated with bacterial lipopolysaccharides. Infect Immun, 63: 3576-3581, 1995

22. Lei G., Flebbe L., Roeder D. and Morrison DC.: Identification and characterization of lipopolysaccharide receptor molecule on mammalian lymphoid cells. Adv Exp Med Biol 256: 445466, 1990

23. Hamada S., Koga T., Nishihara T., Fujiwara T. and Okahasi N.: Characterization and immunobiologic activities of lipopolysaccharides from periodontal bacteria. Adv Dent Res, 2: 284-291, 1988

24. Hamada S., Takada H., Ogawa T., Fujiwara T. and Mihara J.: Lipopolysaccharides of oral anaerobes associated with chronic inflammation: chemical and immunomodulating properties. Intern Rev Immunol, 6: 247-261, 1990

25. Hara Y., Kaneko T., Yoshimura A. and Kato I.: Serum rheumatoid factor induced by intraperitoneal administration of periodontophathic bacterial lipopolysaccharide in mice. $\mathbf{J}$ Periodont Res, 31: 502-507, 1996

26. Novotny A. Heterogeneity of endotoxin. In Reitschel ET, ed. Handbook of endotoxins. Vol I. Amsterdam: Elsevier Science Publishers, pp308, 1984

27. Koga T., Nishihara T., Fujiwara T., Nishizawa T., Okahashi N., Noguchi T. and Hamada S.: Biochemical and immunological properties of lipopolysaccharide (LPS) from
Bacteroides gingivalis and comparison with LPS from Escherichia coli. Infect Immun, 47: 638-647, 1985

28. Ogawa T.: Chemical structure of lipid A from Porphyromonas (Bacteroides) gingivalis lipopolysaccharide. FEBS Lett, 332: 197-201, 1993

29. Hoover C.I.: Electrophoretic heterogeneity of lipopolysaccharides of Actinobacillus actinomycetemcomitans. J Dent Res, 67: 574-576, 1988

30. Perry M.B., MacLean L.M., Brisson J.R. and Wilson ME.: Structures of the antigenic O-polysaccharides of lipopolysaccharides produced by Actinobacillus actinomycetemcomitans serotypes a, c, d and e. Eur J Biochem, 242: 682-688, 1996

31. Fukazawa H., Pei-Ming L., Chii Y., Murakami Y., Mizuno S. and Uehara Y.: Specific inhibition of cytoplasmic protein tyrosine kinases by herbimycin a in vitro. Biochem Pharmacol, 42: 1661-1671, 1991

32. Agro A., Langdon C., Smith F. and Richards C.D.: Prostaglandin $\mathrm{E}_{2}$ enhances interleukin 8 (IL-8) and IL-6 but inhibits GMCSF production by IL-1 stimulated human synovial fibroblasts in vitro. J Rheumatol, 23: 862-868, 1996

33. Negishi M., Ito S. and Hayashi O.: Prostaglandin E receptors in bovine adrenal medulla are coupled to adenylate cyclase via $\mathrm{Gi}$ and to phosphoinositide metabolism in a pertussis toxin-insensitive manner. J Biol Chem, 264: 3916-3923, 1989

34. Brunton L.L., Wiklund R.A., Van Arsdale P.M. and Gilmar AG.: Binding of $\left[{ }^{3} \mathrm{H}\right]$ prostaglandin $\mathrm{E}_{1}$ to putative receptors linked to adenylate cyclase of cultured cell clones. J Biol Chem, 251: 3037-3044, 1976

35. Lenardo M.J. and Baltimore D.: NF-KB. A pleiotropic mediator of inducible and tissue-specific gene control. Cell, 58: 227-229, 1989

36. Standiford T.J., Kunkel S.L., Rolfe M.W., Evanoff H.L., Allen R.M. and Strieter R.M.: Regulation of human alveolar macrophage- and blood monocyte-derived interleukin- 8 by prostaglandin E2 and dexamethasone. Am J Respir Cell Mol Biol, 6: 75-81, 1992

37. Wertheim W.A., Kunkel S.L., Standiford T.J., Burdick M.D. Becker F.S., Wilke C.A., Gilbert A.R., and Strieter R.M.: Regulation of Neutrophil-Derived IL-8: the role of Prostaglandin E2, Dexamethasone, and IL-4. J Immunol, 151: 2166-2175, 1993

38. Zhong W.W., Burke P.A., Drotar M.E., Chavali S.R. and Forse R.A.: Effects of Prostaglandin E2, cholera toxin and 8-brome-cyclic AMP on lipopolysaccharide-induced gene expression of cytokines in human macrophages. Immunology, 84: 446-452, 1995 